\title{
Modeling of Fluid Flow and Heat Transfer in Twin-Roll Casting of Aluminum Alloys
}

\author{
Amit Saxena ${ }^{* 1}$ and Yogeshwar Sahai $* 2$ \\ Department of Materials Science and Engineering, The Ohio State University, Columbus OH 43210-1178, USA
}

A two-dimensional finite element based mathematical model of coupled turbulent fluid flow, heat transfer, and solidification in horizontal twin-roll thin strip casting was developed. Basic formulations for simulating the coupled thermal and flow fields are described in this paper. A $k-\varepsilon$ turbulence model was used to calculate the turbulent viscosity in the melt pool. A variable viscosity model was used to model the mushy region. Inlet velocity, strip/roll heat transfer coefficient, alloy composition, and melt superheat were the main process variables considered. The effect of the above process variables on the sump depth, mean strip exit temperature, roll surface temperature, and temperature gradients inside the roll, was analyzed.

(Received July 2, 2001; Accepted December 4, 2001)

Keywords: aluminum alloys, mathematical modeling, thin strip casting, fluid flow, heat transfer

\section{Introduction}

Twin-roll thin strip casting of aluminum alloys, is an efficient way of obtaining hot-rolled strips directly from the molten metal. In this process, the molten metal is fed from a refractory feed tip into the gap between the steel rolls. The material undergoes a considerable amount of hot rolling before it leaves the rolls. The heat is extracted from the melt by the water-cooled rolls. The process involves solidification of liquid metal and rolling of solidified metal before it leaves the kissing point, which is the point of least roll separation, of the two rollers. Solidification of molten metal starts at the point of first metal-roll contact and is over before the kissing point.

The process has many advantages over the conventional casting technique. The primary advantages are of reduced number of steps of operation and very high cooling rates. A very high cooling rate provides microcrystalline structure with improved mechanical properties. But the process also suffers from many types of defects in the cast strip, which is pronounced at higher casting speeds and inlet temperatures. Increasing the casting speed leads to an increase in the mean exit strip temperature and thus rolling force decreases. ${ }^{1)}$ The major defects encountered are the centerline segregation, heat line formation, sticking, and surface cracks due to the induced thermo-mechanical stresses. Extent or the severity of these defects is very sensitive to the process conditions. Proper optimization of these process conditions can lead to minimization of these defects. Hence, a detailed analysis of fluid flow and heat transfer is necessary to find the effect of these various process parameters on the extent of these defects.

Various mathematical models ${ }^{2-7)}$ have been suggested in the literature to predict the fluid flow, heat transfer, and solidification in twin-roll casters. Most of the papers deal with fluid flow modeling in vertical twin-roll casters, but only a few papers ${ }^{6,7)}$ deal with the fluid flow modeling in horizontal twin-roll casters. Miyazawa and Szekely ${ }^{2)}$ were the first

\footnotetext{
${ }^{* 1}$ Graduate Student, The Ohio State University. Present address: Computational Fluid Dynamics Research Corporation, 215 Wynn Drive, Huntsville, AL 35806, USA

*2Corresponding author, E-mail: Sahai.1@ osu.edu
}

ones to develop a mathematical model for heat transfer and fluid flow calculations in solid and molten phases for a vertical twin-roll caster for aluminum. Mo and Hoydal ${ }^{6)}$ developed a model for calculation of temperature, melt flow, deformation, and stress in aluminum twin roll casting. The model incorporated the free and forced convection in the melt, solidification shrinkage, and latent heat release in the mushy zone, and the inhomogeneous deformation of the solidified part of the strip.

In the present work, a steady state two-dimensional finite element model was developed, which employs a single set of conservation equations for the liquid, mushy, and solid phases. A variable viscosity model suggested in Ref. 8) was used for the modeling of the mushy zone. The model involves coupling of fluid flow and heat transfer equations. Commercial available finite element software, FIDAP, was used to generate mesh and to solve the transport equations in the calculation domain. The two-equation $k-\varepsilon$ model was used for turbulence considerations. The velocity field and temperature distribution were obtained for various values of process variables. The mathematical model was used to investigate the effect of process variables such as casting speed, contact strip/roll heat transfer coefficient, alloy composition, and melt superheat on size and shape of sump, mean exit strip temperatures, temperature distribution on the roll surface, and temperature gradients inside the roll.

\section{Mathematical Model}

\subsection{Numerical model and governing equations}

A two-dimensional schematic of the horizontal twin-roll thin strip caster with all dimensions is illustrated in Fig. 1. The molten metal is fed into the roll gap through the refractory metal feeding inlet tip. The inlet velocity of the molten metal was kept equal to the velocity of the rolls rotating in opposite directions. The rolls were cooled by recirculating water. The solidification starts at the roll surface and progresses towards the centerline. Unlike the thin strip casting of steel, the solidification, in case of aluminum alloys, is completed before the kissing point (minimum separation) of the rolls. 


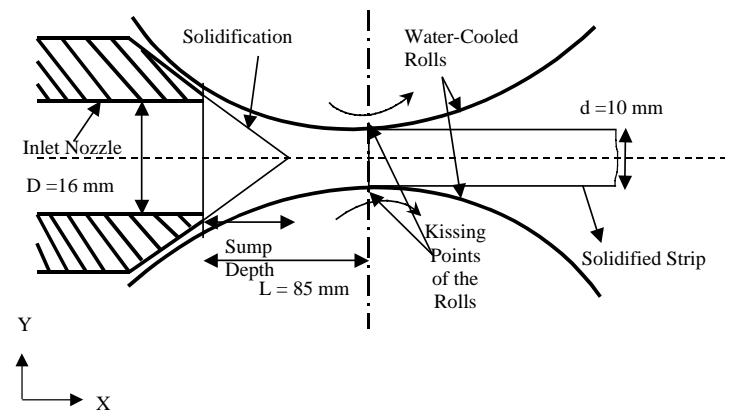

Fig. 1 Schematic representation of the thin strip casting process with dimensions.

Hence the strip undergoes some reduction after complete solidification. Following assumptions were used in developing this mathematical model:

1. The process is at steady state, and after a small initial transient period, process variables do not change with time.

2. Since the width to thickness ratio is very large, so the end effects can be ignored and the geometry of the process can be approximated as two-dimensional.

3. Liquid aluminum alloy is incompressible and the fluid flow characteristic is Newtonian in nature.

4. Material properties (except viscosity and specific heat) were temperature independent.

5. A constant value of contact heat transfer coefficient along the strip/roll interface was assumed.

6. There was no slip between the roll and the solidified strip.

7. Heat losses by radiation were negligible.

8. The solidification process was assumed to be growth controlled.

Under the above assumptions, the following transport equations were solved in the calculation domain:

1. Continuity Equation

2. Turbulent Navier-Stokes Equation

3. Conservation of Thermal Energy Equation

\subsection{Mushy zone modeling}

Since most of the casting materials are alloys and have a melting range, modeling of the mushy zone is an important aspect of a multi-phase problem. In the present study, the phase change viscosity model provided by FIDAP $^{8)}$ has been used for dealing with the phase change problem in a binary phase alloy. The change of phase from liquid to solid of a material solidifying under the action of a temperature field can be modeled in FIDAP by treating the material as a liquid whose viscosity changes from its liquid phase value to an extremely large value. In this model, the presence of mushy zone can be represented by a suitable gradient of the viscosity over a range of temperatures between liquidus and solidus. Since the flow within the rolls is turbulent in nature, an effective viscosity term, which is the sum of laminar and turbulent viscosity, is included in the governing equations. As the solidification takes place, the turbulence within the melt pool dampens and finally the turbulent viscosity reaches zero at complete solidification and the movement of the solidified portion within the mushy zone is evidently laminar. Hence the viscosity model

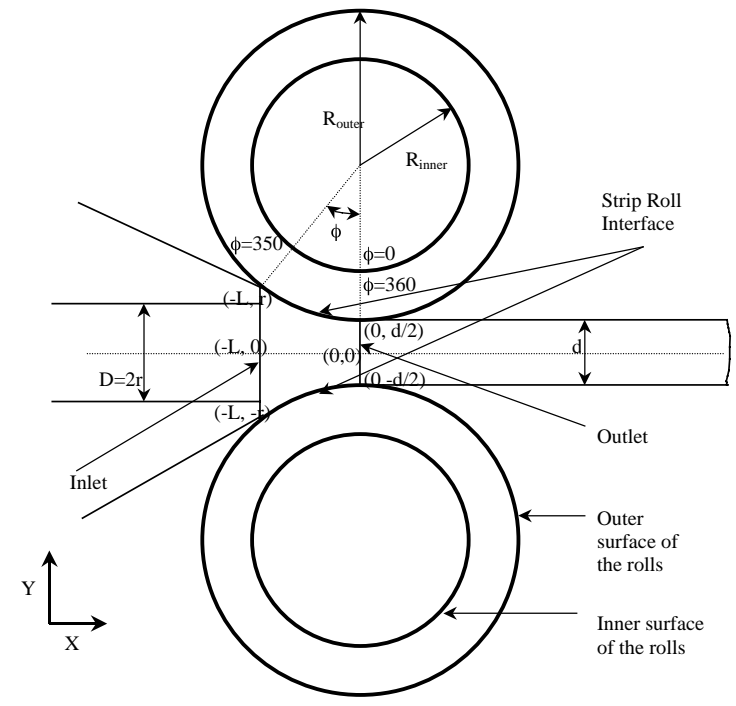

Fig. 2 Schematic representation of the regions where boundary conditions are specified and the coordinate system.

in the present study allows the turbulent viscosity to be zero in the solid zone and decay gradually to zero in some transition zone. Details of this model can be found elsewhere. ${ }^{8)}$

\subsection{Initial and boundary conditions}

Figure 2 shows the coordinate system and the regions where boundary conditions were specified. Initial and boundary conditions were specified on each segment of the boundary of the computational domain, which consisted of inlet metal feeding tip, outer surface of the rolls, inner surface of rolls, and the strip/roll interface as shown in Fig. 2. The initial velocity of $u(x, y, 0)=v_{\text {inlet }}$ and the inlet temperature of $T(x, y, 0)=T_{\text {inlet }}$ were taken as the initial conditions in the whole computational domain.

Feed Tip

$$
\begin{aligned}
& x=-L, \quad-r \leq y \leq r \\
& u=v_{\text {inlet }}, \quad v=0, \quad T=T_{\text {inlet }}, \quad E=C_{\mathrm{p}} T_{\text {inlet }}
\end{aligned}
$$

where,

$$
\begin{aligned}
T_{\text {inlet }} & =T_{\text {liquid }}+T_{\text {superheat }} \\
k & =0.001 v_{\text {inlet }}^{2}, \quad \varepsilon=\frac{10 k^{1.5}}{\delta}
\end{aligned}
$$

where, $\delta$ is the characteristic thickness of shear width. In the present work, $\delta$ was taken as the diameter of the inlet tube.

$$
\frac{\partial k}{\partial x}=0, \quad \frac{\partial \varepsilon}{\partial x}=0, \quad \frac{\partial k}{\partial y}=0, \quad \frac{\partial \varepsilon}{\partial y}=0
$$

Outer Surface of Rolls

$$
r=R_{\text {outer }}, \quad 0 \leq \bar{\theta} \leq 2 \pi-\phi
$$

Tangential and normal velocities were specified on this surface. The outer surface of the roll is in contact with ambient atmosphere at the reference temperature $T_{\text {ref,atm }}$ taken to be $300 \mathrm{~K}$. An effective heat transfer coefficient of $50 \mathrm{~W} / \mathrm{m}^{2} \mathrm{~K}$ was specified.

$$
q_{\text {atm }}=-k_{\text {atm }} \frac{\partial T}{\partial r}=h_{\text {effective }}\left(T-T_{\text {ref,atm }}\right)
$$




\section{Inner Surface of Rolls}

$$
r=R_{\text {inner }}, \quad 0 \leq \bar{\theta} \leq 2 \pi
$$

Tangential and normal velocities were specified on this surface.

$$
u_{\text {tang, } \text { roll }}=\omega R_{\text {inner }}, \quad u_{\text {normal, } \text { roll }}=0
$$

The recirculating water cools the inner surface of the rolls. The convective heat transfer coefficient due to the heat transfer from the rolls to the water was specified to be $10000 \mathrm{~W} / \mathrm{m}^{2} \mathrm{~K}$. The reference temperature of the water was specified to be $313 \mathrm{~K}$.

$$
q_{\text {water }}=-k_{\text {water }} \frac{\partial T}{\partial r}=h_{\text {conv,water/roll }}\left(T-T_{\text {ref,water }}\right)
$$

\section{Strip/Roll Interface}

$$
r=R_{\text {outer }}, \quad 2 \pi-\phi \leq \bar{\theta} \leq 2 \pi
$$

Tangential and normal velocities of the strip were specified on this surface.

$$
u_{\text {tang,strip }}=\omega R_{\text {outer }}, \quad u_{\text {normal,strip }}=0
$$

In the present work, the value of the contact heat transfer coefficient was identified to be an important process parameter, and hence the model was run for various values of this parameter ranging from 1000 to $15000 \mathrm{~W} / \mathrm{m}^{2} \mathrm{~K}$.

$$
\begin{aligned}
q_{\text {roll }} & =-k_{\text {roll }} \frac{\partial T}{\partial r}=h_{\text {contact,strip/roll }}\left(T-T_{\text {ref,roll }}\right) \\
k & =0, \quad \varepsilon=0
\end{aligned}
$$

Outlet

$$
\begin{aligned}
x & =0, & \frac{-d}{2} \leq y \leq \frac{d}{2} \\
\frac{\partial u}{\partial x}=0, & \frac{\partial v}{\partial x}=0, & \frac{\partial k}{\partial x}=0, \\
\frac{\partial \varepsilon}{\partial x}=0, & \frac{\partial k}{\partial y}=0, & \frac{\partial \varepsilon}{\partial y}=0
\end{aligned}
$$

The above governing equations were solved numerically using a two-dimensional finite element model developed on FIDAP. Results were obtained for $\mathrm{Al}-4.5 \% \mathrm{Cu}$ and $\mathrm{Al}-$ $1.1 \% \mathrm{Mg}$ alloys for varying values of contact heat transfer coefficient, inlet velocity, and melt superheat. The thermophysical data and casting conditions for $\mathrm{Al}-4.5 \% \mathrm{Cu}$ alloy for fluid flow, heat transfer, and solidification is given in Table 1.

\section{Results and Discussion}

The mathematical model was run for different sets of values of contact strip/roll heat transfer coefficient, $h_{\text {contact,strip/roll, }}$ inlet velocity, $v_{\text {inlet }}$, and melt superheat, $T_{\text {superheat }}$. The inlet velocity was varied from 1 to $20 \mathrm{~mm} / \mathrm{s}$,

\begin{tabular}{|c|c|c|}
\hline Symbol & Value & Reference \\
\hline$C_{\mathrm{p}}$ & $1179.0 \mathrm{~J} / \mathrm{kg} \mathrm{K}$ & (9) \\
\hline$d$ & $10 \mathrm{~mm}$ & \\
\hline$D$ & $16 \mathrm{~mm}$ & \\
\hline$k^{\prime}$ & $120 \mathrm{~W} / \mathrm{mK}$ & \\
\hline$L$ & $85 \mathrm{~mm}$ & \\
\hline$h_{\text {contact,strip/roll }}$ & $1000-15000 \mathrm{~W} / \mathrm{m}^{2} \mathrm{~K}$ & \\
\hline$h_{\text {conv,water/roll }}$ & $10000 \mathrm{~W} / \mathrm{m}^{2} \mathrm{~K}$ & \\
\hline$h_{\text {effective }}$ & $50 \mathrm{~W} / \mathrm{m}^{2} \mathrm{~K}$ & \\
\hline$H_{f}$ & $392000 \mathrm{~J} / \mathrm{kg}$ & (9) \\
\hline Roll Material & Steel & \\
\hline Roll Thickness & $50 \mathrm{~mm}$ & \\
\hline$R_{\text {inner }}$ & $400 \mathrm{~mm}$ & \\
\hline$R_{\text {outer }}$ & $450 \mathrm{~mm}$ & \\
\hline$T_{\text {inlet }}$ & $940-980 \mathrm{~K}$ & \\
\hline$T_{\text {liquidus }}$ & $920 \mathrm{~K}$ & \\
\hline$T_{\text {ref,roll }}$ & $300 \mathrm{~K}$ & \\
\hline$T_{\text {ref,water }}$ & $313 \mathrm{~K}$ & \\
\hline$T_{\text {solidus }}$ & $842 \mathrm{~K}$ & \\
\hline$T_{\text {superheat }}$ & $20-60 \mathrm{~K}$ & \\
\hline$v_{\text {inlet }}$ & $1-20 \mathrm{~mm} / \mathrm{s}$ & \\
\hline$\rho_{\text {liquid }}$ & $2438 \mathrm{~kg} / \mathrm{m}^{3}$ & (9) \\
\hline$\rho_{\text {solid }}$ & $2580 \mathrm{~kg} / \mathrm{m}^{3}$ & (9) \\
\hline
\end{tabular}
the contact strip/roll heat transfer coefficient was varied from 1000 to $15000 \mathrm{~W} / \mathrm{m}^{2} \mathrm{~K}$, and the melt superheat was varied from 20 to $60 \mathrm{~K}$. The simulations were performed for Al$4.5 \% \mathrm{Cu}$ and $\mathrm{Al}-1.1 \% \mathrm{Mg}$ alloys. Velocity vectors, turbulent kinetic energy contours, viscous dissipation rate of turbulent kinetic energy contours, and temperature contours were obtained for each case. An inlet velocity of $15 \mathrm{~mm} / \mathrm{s}$, a con-
Table 1 Thermophysical data for $\mathrm{Al}-4.5 \% \mathrm{Cu}$ and the casting conditions for the specific geometry.

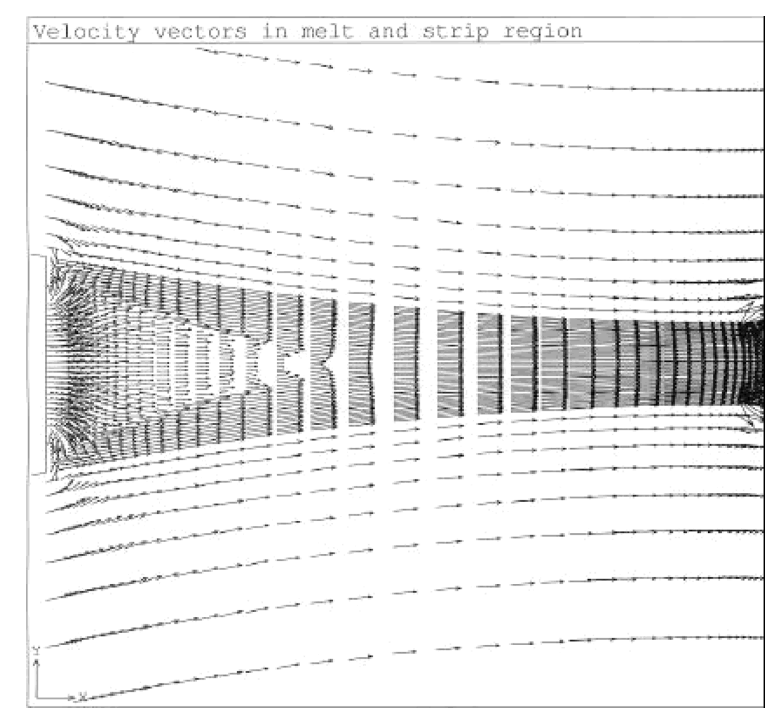

Fig. 3 Typical velocity distribution in the melt pool for inlet velocity of $15 \mathrm{~mm} / \mathrm{s}$, contact strip/roll heat transfer coefficient of $10000 \mathrm{~W} / \mathrm{m}^{2} \mathrm{~K}$, and melt superheat of $30 \mathrm{~K}$.

tact strip/roll heat transfer coefficient of $10000 \mathrm{~W} / \mathrm{m}^{2} \mathrm{~K}$, and a melt superheat of $30 \mathrm{~K}$ were taken to be the standard conditions. Figures 3, 4, and 5 show a typical velocity vectors, turbulent kinetic energy contours and temperature contours, respectively, for the standard case for $\mathrm{Al}-4.5 \% \mathrm{Cu}$ alloy.

Figure 3 shows the velocity vectors distribution in the melt and strip region of the computational domain. The velocity in the region between the metal feed tip and the rolls is quite low compared to the inlet velocity. Due to decrease in the cross-sectional area, the average velocity of metal (liquid and solidified) increases as it progresses away from the inlet. Solidified metal moves with roll velocity and liquid velocity is 


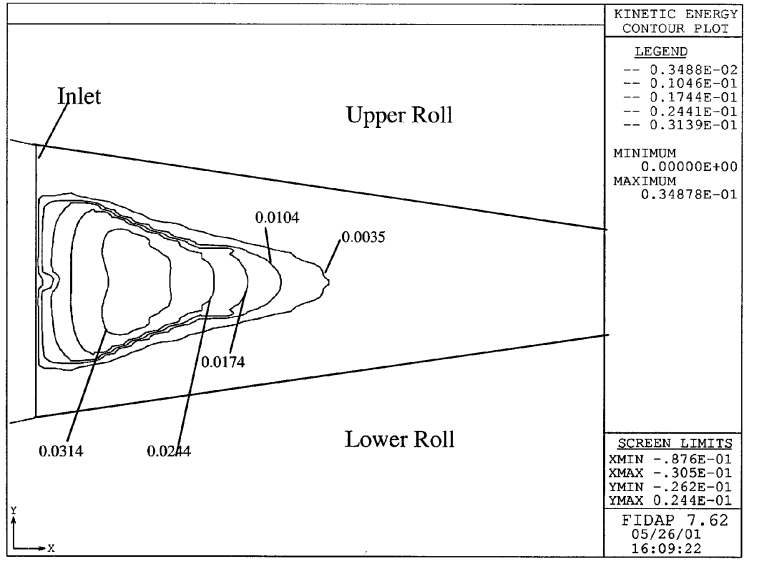

Fig. 4 Typical turbulent kinetic energy contours in the melt pool for inlet velocity of $15 \mathrm{~mm} / \mathrm{s}$, contact strip/roll heat transfer coefficient of $10000 \mathrm{~W} / \mathrm{m}^{2} \mathrm{~K}$, and melt superheat of $30 \mathrm{~K}$. The turbulent kinetic energy contours value are in $\mathrm{m}^{2} \mathrm{~s}^{2}$ units.

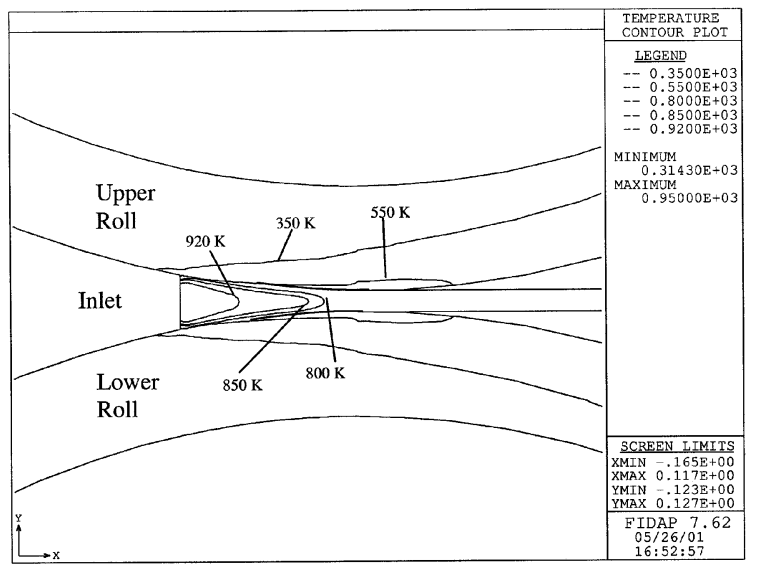

Fig. 5 Typical temperature contours in the melt and the rolls for inlet velocity of $15 \mathrm{~mm} / \mathrm{s}$, contact strip/roll heat transfer coefficient of $10000 \mathrm{~W} / \mathrm{m}^{2} \mathrm{~K}$, and melt superheat of $30 \mathrm{~K}$

much slower than solid velocity. The velocity profile becomes quite uniform in the solid region. The central region of the melt is more turbulent $\left(0.0314 \mathrm{~m}^{2} \mathrm{~s}^{2}\right)$ than the region near to the rolls $\left(0.0035 \mathrm{~m}^{2} \mathrm{~s}^{2}\right)$ as can be seen from Fig. 4 .

Figure 5 shows the temperature contours $(920,850,800$, 550 , and $350 \mathrm{~K})$ in the melt, solidified strip and roll region of the computational domain. As shown in Fig. 5, the solidification (i.e. solidus temperature of $842 \mathrm{~K}$ for $\mathrm{Al}-4.5 \% \mathrm{Cu}$ alloy) gets completed well before the kissing point of the rolls. The liquidus temperature of $\mathrm{Al}-4.5 \% \mathrm{Cu}$ alloy is $920 \mathrm{~K}$. The recirculating water cools the inner surface of the rolls keeping the inner surface of the rolls at a temperature in the range of 325 to $350 \mathrm{~K}$ for different cases of inlet velocity and contact strip/roll heat transfer coefficient.

Figure 6 shows the position of the liquidus (liquidus temperature line) and solidus (solidus temperature line) lines for $\mathrm{Al}-4.5 \% \mathrm{Cu}$ for the standard conditions. The liquidus and solidus temperatures for $\mathrm{Al}-4.5 \% \mathrm{Cu}$ are 920 and $842 \mathrm{~K}$, respectively. The region between the liquidus and solidus lines where liquid and solid coexist is the mushy zone. Sump depth is defined to be the distance from the inlet to the point where complete solidification has taken place (i.e. on the solidus line).

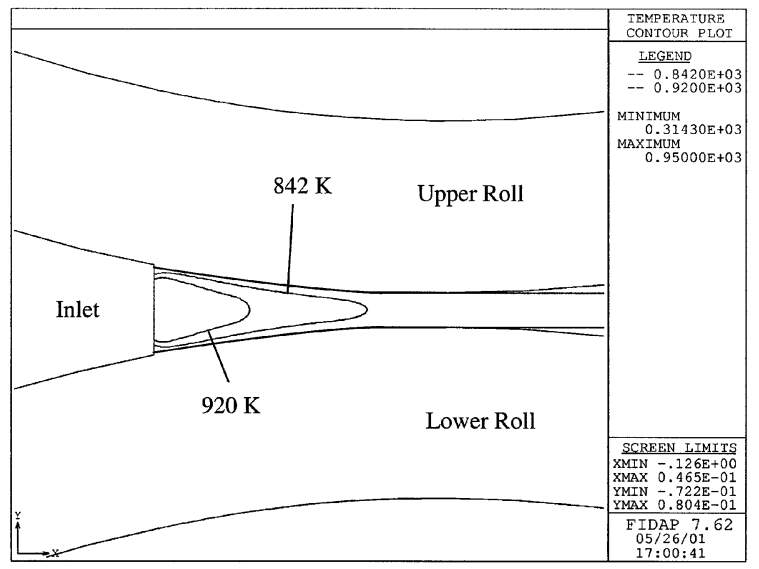

Fig. 6 Position of liquidus and solidus lines in the melt region for Al-4.5\% Cu alloy for inlet velocity of $15 \mathrm{~mm} / \mathrm{s}$, contact strip/roll heat transfer coefficient of $10000 \mathrm{~W} / \mathrm{m}^{2} \mathrm{~K}$, and melt superheat of $30 \mathrm{~K}$.

The severity of centerline segregation is strongly related to the sump depth. Minimization of the sump depth plays an important role in improving the quality of the as-cast strips. Sump depth is a function of process variables like inlet velocity, contact strip/roll heat transfer coefficient, melt superheat, alloy composition, and nozzle thickness.

\subsection{Sump depth}

As previously discussed, the quality of the cast strip depends on the sump depth. It is important to discuss the effect of various process variables on the sump depth. The simulations were performed for $\mathrm{Al}-4.5 \% \mathrm{Cu}$ alloy.

\subsubsection{Effect of inlet velocity and contact strip/roll heat transfer coefficient}

Figure 7 shows the effect of casting speed and strip/roll heat transfer coefficient on the sump depth. Sump depth increases with increasing inlet velocity and decreasing strip/roll heat transfer coefficient. Variation in inlet velocity has the larger influence on the sump depth, except at very low inlet velocity of $1 \mathrm{~mm} / \mathrm{s}$. As the inlet velocity is increased, the strip/roll heat transfer coefficient influences the sump depth. The value of strip/roll heat transfer coefficient dictates the removal of sensible heat from the aluminum strip to the steel rolls. The tip set back L, i.e. the distance from the inlet to the kissing point of the rolls is taken to be $85 \mathrm{~mm}$ for the present study.

\subsubsection{Effect of melt superheat}

Melt superheat is defined as the excess heat of the alloy above the liquidus temperature. It is the difference between the inlet and the liquidus temperature of the alloy. Figure 8 shows the effect of melt superheat on the sump depth. There is a little variation (i.e. 61 to $70 \mathrm{~mm}$ ) in the sump depth with the increase in melt superheat. This is due to the fact that the latent heat released from solidification is much higher than the superheat in the alloy. Hence melt superheat does not influence the sump depth to a large extent.

\subsubsection{Effect of alloy composition}

The extent of the mushy region is strongly dependent on the solute composition of these alloys. Figure 9 shows the effect of alloy composition (for $\mathrm{Al}-4.5 \% \mathrm{Cu}$ and $\mathrm{Al}-1.1 \% \mathrm{Mg}$ alloys) on the sump depth at different inlet velocity and a constant value of strip/roll heat transfer coefficient. At low 


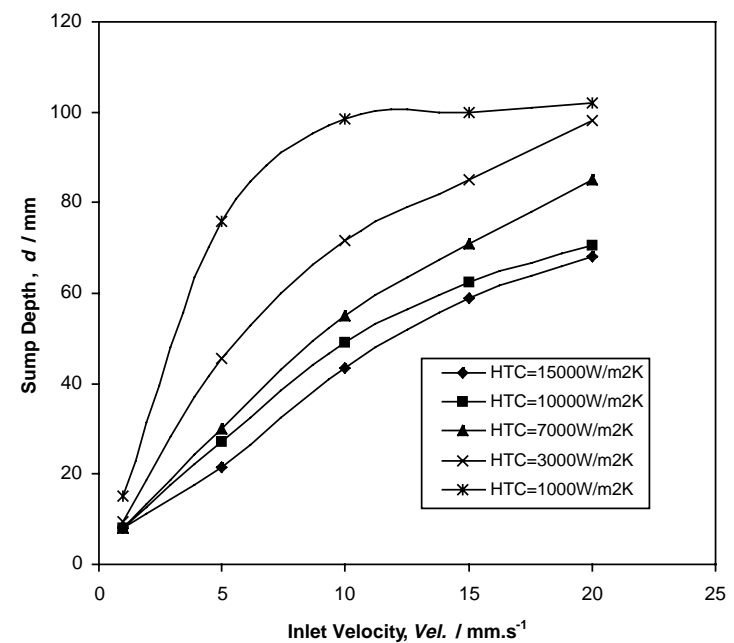

Fig. 7 Variation of sump depth with varying inlet velocity and strip/roll heat transfer coefficient and at constant melt superheat of $30 \mathrm{~K}$.

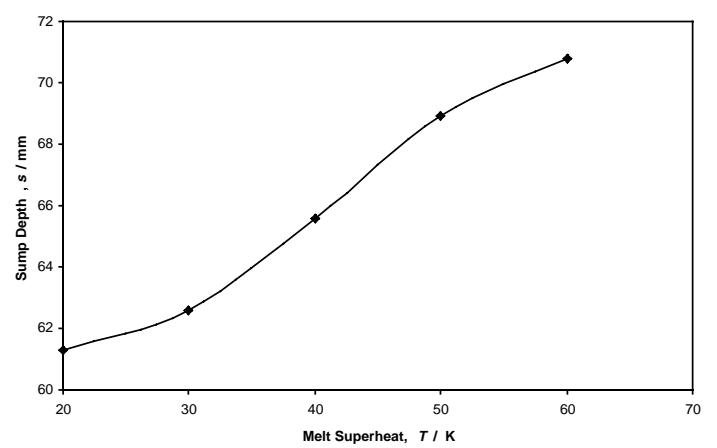

Fig. 8 Variation of sump depth with constant inlet velocity of $15 \mathrm{~mm} / \mathrm{s}$ and strip/roll heat transfer coefficient of $10000 \mathrm{~W} / \mathrm{m}^{2} \mathrm{~K}$ and varying the melt superheat.

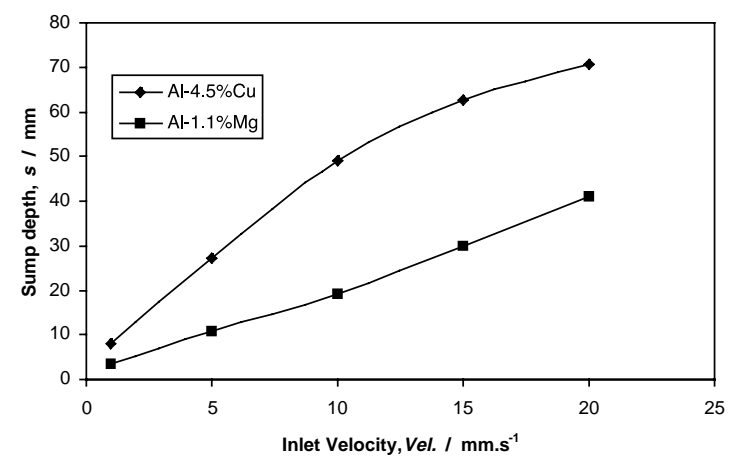

Fig. 9 Variation of sump depth for $\mathrm{Al}-4.5 \% \mathrm{Cu}$ and $\mathrm{Al}-1.1 \% \mathrm{Mg}$ alloys for varying inlet velocities at constant strip/roll heat transfer coefficient of $10000 \mathrm{~W} / \mathrm{m}^{2} \mathrm{~K}$ and melt superheat of $30 \mathrm{~K}$.

inlet velocity of $1 \mathrm{~mm} / \mathrm{s}$, there is a small difference $(5 \mathrm{~mm})$ on the sump depth. But at high inlet velocities the difference in the sump depth becomes large $(35 \mathrm{~mm}$ at inlet velocity of $20 \mathrm{~mm} / \mathrm{s}$ ). Hence the alloy composition also influences the sump depth at high inlet velocities.

\subsection{Strip exit temperature}

Contact strip/roll heat transfer coefficient and inlet velocity also has a strong effect on the strip exit temperature. The strip exit temperature is an important parameter to be studied. It affects the thermal gradient within the through thickness of the

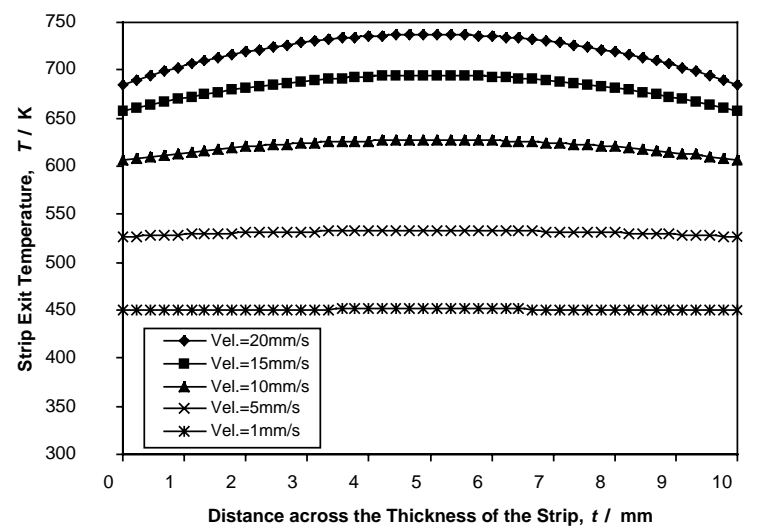

Fig. 10 Variation of strip exit temperatures at the kissing point of rolls for various inlet velocities and at constant strip/roll heat transfer coefficient of $10000 \mathrm{~W} / \mathrm{m}^{2} \mathrm{~K}$ and constant melt superheat of $30 \mathrm{~K}$.

strip, which was taken to be $10 \mathrm{~mm}$. Variation of inlet velocity at constant strip/roll heat transfer coefficient and variation of strip/roll heat transfer coefficient at constant velocity were studied. The variation of the melt superheat on the strip exit temperature was found out to be negligible, hence it is not presented here.

\subsubsection{Effect of inlet velocity}

Figure 10 shows the effect of inlet velocity on the strip exit temperatures. When the inlet velocity is varied from 1 to $20 \mathrm{~mm} / \mathrm{s}$, the mean strip exit temperature changes from 450 to $720 \mathrm{~K}$. At higher inlet velocities, the distance at which complete solidification takes place is far away from the inlet. So it becomes evident that higher strip exit temperatures are predicted for higher inlet velocities. Apart from higher strip exit temperatures, the temperature difference through thickness i.e. from the surface of the strip to the center is also large at higher inlet velocities. For lower inlet velocity of $1 \mathrm{~mm} / \mathrm{s}$, the through thickness temperature variation is only $2 \mathrm{~K}$, as compared to $53 \mathrm{~K}$ in case of $20 \mathrm{~mm} / \mathrm{s}$.

\subsubsection{Effect of contact strip/roll heat transfer coefficient}

Figure 11 shows the effect of strip/roll heat transfer coefficient on the strip exit temperature. The mean strip exit temperatures vary from 672 to $854 \mathrm{~K}$ as the strip/roll heat transfer coefficient is varied from 1000 to $15000 \mathrm{~W} / \mathrm{m}^{2} \mathrm{~K}$ at a constant inlet velocity of $15 \mathrm{~mm} / \mathrm{s}$. The mean strip exit temperature changes from 655 to $660 \mathrm{~K}$, when the strip/roll heat transfer coefficient is varied from 10000 to $15000 \mathrm{~W} / \mathrm{m}^{2} \mathrm{~K}$, which indicates that the effect of higher strip/roll heat transfer coefficient is less at higher values.

\subsection{Surface temperature of the rolls}

Contact strip/roll heat transfer coefficient and inlet velocity also dictates the temperature distribution on the outer surface of the rolls. As the rolls constantly rotate, a part of it always makes a periodic contact with the melt. As soon as the surface looses contact with the melt, it starts cooling due to the quenching effect of atmosphere outside and the flow of recirculating water from inside the rolls. In each rotation, the rolls undergo a thermal cycle. It is of great importance to control the surface temperature of the rolls and its variation. In the present study, the variation of surface temperature with contact strip/roll heat transfer coefficient and inlet velocity is 


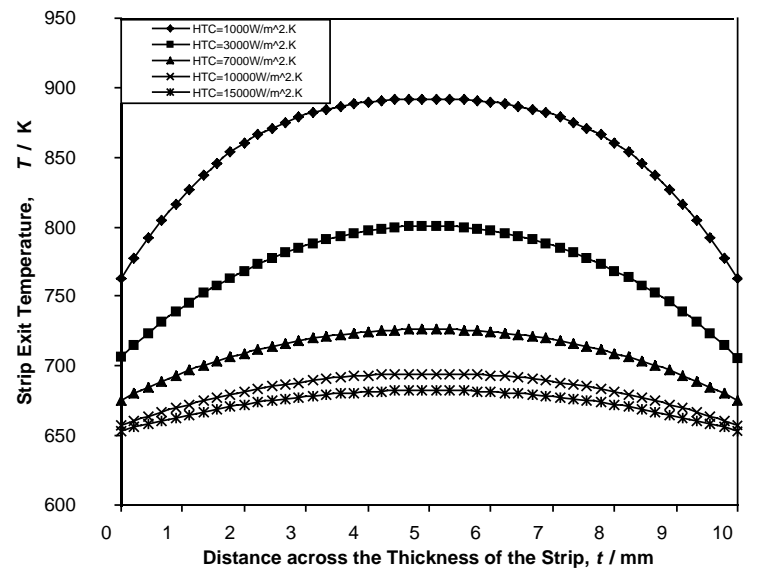

Fig. 11 Variation of strip exit temperatures at the kissing point of rolls for various strip roll heat transfer coefficients and at constant inlet velocity of $15 \mathrm{~mm} / \mathrm{s}$ and constant melt superheat of $30 \mathrm{~K}$

studied.

\subsubsection{Effect of inlet velocity}

The effect of inlet velocity on the roll surface temperature plotted in into two Figs., namely, 12 and 13. Figure 12 shows the effect of inlet velocity on the resulting surface temperature distribution on the part of the upper roll not in contact with the strip. Figure 13 shows the effect of inlet velocity on the resulting surface temperature distribution on the part of upper roll in contact with the melt. The $0^{\circ}$ and $360^{\circ}$ point on the roll correspond to the kissing point of the rolls or the point of least separation of rolls. The upper roll rotates in the counterclockwise direction. An angle of $350^{\circ}$ corresponds to the first point on the roll, which comes in contact with the melt. The points represented by angles between $350^{\circ}$ and $360^{\circ}$ are always in contact with the solidifying strip and the points represented by angles between $0^{\circ}$ and $350^{\circ}$ are not in contact with the strip. At $0^{\circ}$ or $360^{\circ}$ (i.e. at the kissing point) the temperature is the highest for all cases, as can be seen in Fig. 12. It varies from 450 to $609 \mathrm{~K}$ as the inlet velocity is varied from 1 to $20 \mathrm{~mm} / \mathrm{s}$. This indicates that inlet velocity has a large influence on the temperature distribution on the outer surface of the rolls. The temperature drops very quickly after the roll looses contact with the strip. As the angle increases, the rate of temperature drop decreases and the surface temperature of the rolls become nearly constant.

At an angle of $350^{\circ}$, the rolls come in contact with the melt and the temperature rises appreciably (more than $300 \mathrm{~K}$ in case of $1 \mathrm{~mm} / \mathrm{s}$ ) for all the cases, as can be seen from Fig. 13 . The rate of temperature rise is maximum at the lowest inlet velocity. This is because at low inlet velocity, more heat is transferred per unit area from melt to the rolls at a constant strip/roll heat transfer coefficient. For all the cases, the temperature reaches a maximum value and then drops because of the quenching effect of the recirculating water inside the rolls becomes large enough. The point of maximum temperature differs considerably for various cases. For the inlet velocity of $1 \mathrm{~mm} / \mathrm{s}$, the maximum temperature is reached near to inlet, and this maxima lie almost vertically above the point in the melt region of the strip at which complete solidification takes place. Roll surface temperature gradually falls once complete solidification has taken place. The point of maximum tem-

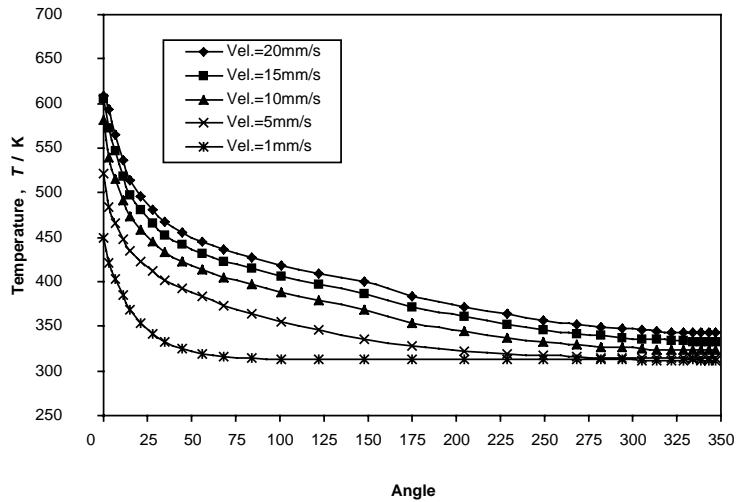

Fig. 12 Effect of inlet velocity on the temperature distribution along the outer surface of the upper roll not in contact with the strip for constant strip/roll heat transfer coefficient of $10000 \mathrm{~W} / \mathrm{m}^{2} \mathrm{~K}$ and constant melt superheat of $30 \mathrm{~K}$.

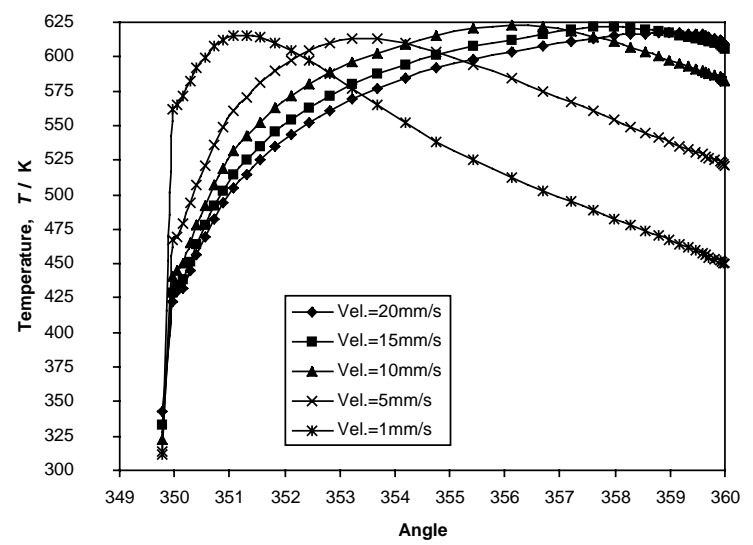

Fig. 13 Effect of inlet velocity on the temperature distribution along the outer surface of the upper roll in contact with the strip for constant strip/roll heat transfer coefficient of $10000 \mathrm{~W} / \mathrm{m}^{2} \mathrm{~K}$ and constant melt superheat of $30 \mathrm{~K}$.

perature shifts towards the exit point as the inlet velocity is increased. This is because at a high inlet velocity the point of complete solidification is near the exit point, which corresponds to the $360^{\circ}$ on the rolls.

\subsubsection{Effect of contact strip/roll heat transfer coefficient:}

The effect of strip/roll heat transfer coefficient is also plotted in two Figs., namely, 14 and 15. Figure 14 shows the effect of contact strip/roll heat transfer coefficient on the resulting temperature distribution on the outer surface of the upper roll not in contact with the strip. Figure 15 shows the effect of contact strip/roll heat transfer coefficient on the resulting temperature distribution on the outer surface of upper roll in contact with the strip.

At $0^{\circ}$ or $360^{\circ}$ (i.e. at the kissing point) the temperature is the highest for all cases, as can be seen in Fig. 14. It varies from 460 to $605 \mathrm{~K}$ as the contact strip/roll heat transfer coefficient is varied from 1000 to $15000 \mathrm{~W} / \mathrm{m}^{2} \mathrm{~K}$. The temperature drops very quickly after the roll looses contact with the strip. As the angle increases, the rate of temperature drop decreases and the surface temperature of the rolls become nearly constant. The temperature of the rolls not in contact with the melt is dictated by the heat transfer coefficient between the rolls and air $\left(50 \mathrm{~W} / \mathrm{m}^{2} \mathrm{~K}\right)$ and heat transfer coefficient between the rolls and recirculating water $\left(10000 \mathrm{~W} / \mathrm{m}^{2} \mathrm{~K}\right)$. 


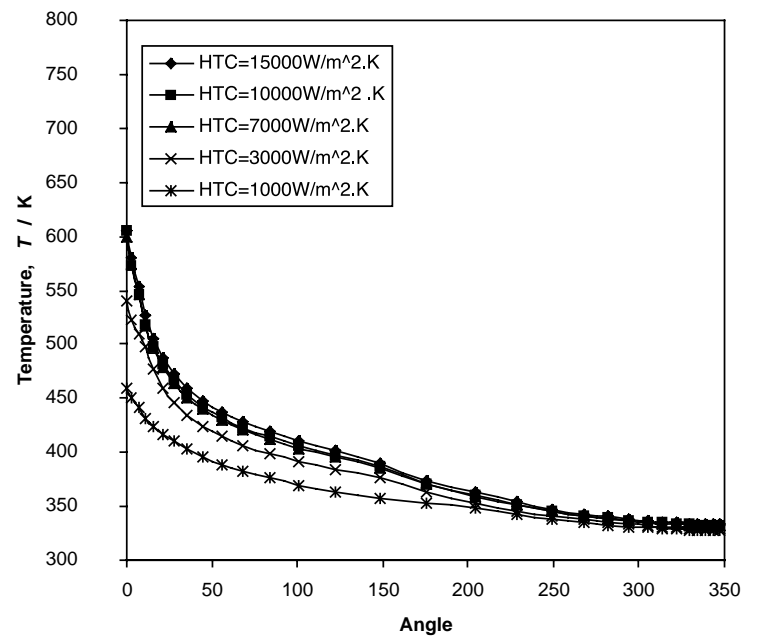

Fig. 14 Effect of contact strip/roll heat transfer coefficient on the temperature distribution along the outer surface of the upper roll not in contact with the strip for constant inlet velocity of $10 \mathrm{~mm} / \mathrm{s}$ and constant melt superheat of $30 \mathrm{~K}$.

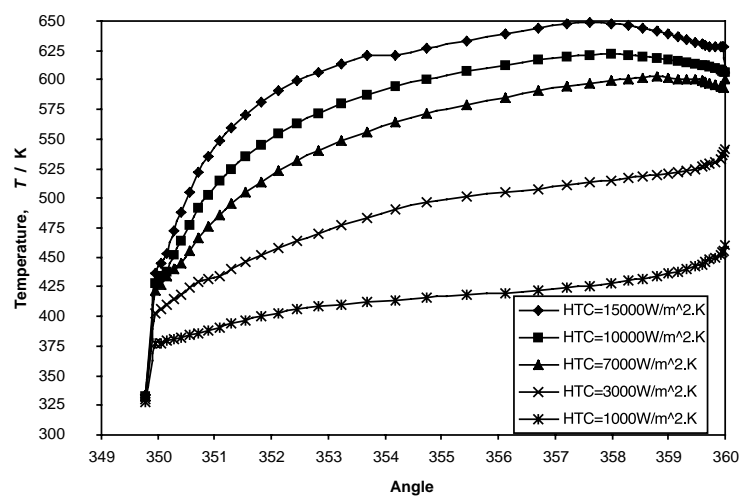

Fig. 15 Effect of contact strip/roll heat transfer coefficient inlet on the temperature distribution along the outer surface of the upper roll in contact with the strip for constant inlet velocity of $10 \mathrm{~mm} / \mathrm{s}$ and constant melt superheat of $30 \mathrm{~K}$.

The temperature rises as soon as the melt touches the roll and increases rapidly and then the rate of temperature rise gradually decreases as can be seen in Fig. 15. For a higher heat transfer coefficient, for example $15000 \mathrm{~W} / \mathrm{m}^{2} \mathrm{~K}$, the temperature of the roll increases and then becomes constant when the temperature difference between the solidified strip and the roll decreases. While for a lower heat transfer coefficient, for example $1000 \mathrm{~W} / \mathrm{m}^{2} \mathrm{~K}$, the roll surface temperature continues to increase till the exit point because the temperature difference between the roll and the strip is still large.

\subsection{Through thickness temperature distribution in rolls}

The temperature distribution across the through thickness of the upper roll for the standard case i.e. inlet velocity of $15 \mathrm{~mm} / \mathrm{s}$, contact strip/roll heat transfer coefficient of $10000 \mathrm{~W} / \mathrm{m}^{2} \mathrm{~K}$, and melt superheat of $30 \mathrm{~K}$, has been studied. Figure 16 shows the temperature distribution across the through thickness of the upper roll at various roll angles. The through thickness of the rolls was $50 \mathrm{~mm}$.

The distribution of the nodes in through thickness direction was such that the node density near the outer surface of the roll was greater than the node density near the inner surface

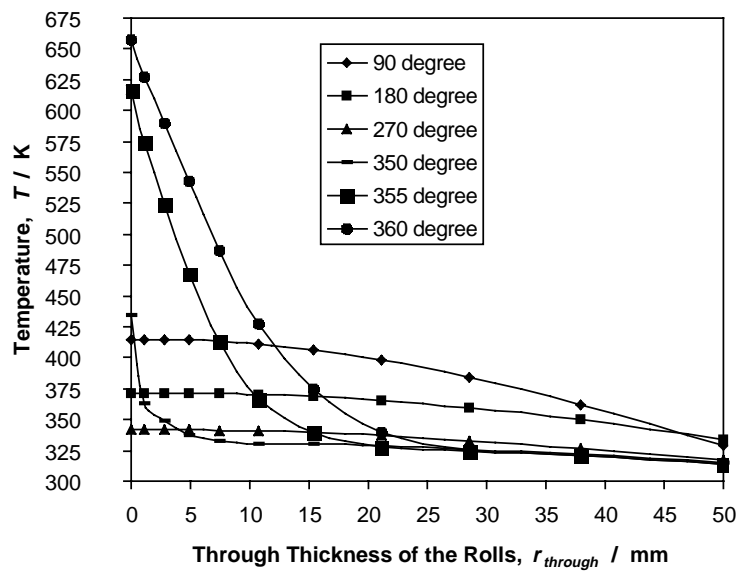

Fig. 16 Temperature distribution across the through thickness of the upper roll at various roll angles for inlet velocity of $15 \mathrm{~mm} / \mathrm{s}$, contact strip/roll heat transfer coefficient of $10000 \mathrm{~W} / \mathrm{m}^{2} \mathrm{~K}$, and melt superheat of $30 \mathrm{~K}$.

of the rolls. $0 \mathrm{~mm}$ in Fig. 16 corresponds to the outer surface of the roll and $50 \mathrm{~mm}$ corresponds to the inner surface of the roll. The value of heat transfer coefficient between rolls and water was taken to be $10000 \mathrm{~W} / \mathrm{m}^{2} \mathrm{~K}$ and the initial temperature of water was assumed to be $313 \mathrm{~K}$. The value of heat transfer coefficient between rolls and atmosphere is taken to be $50 \mathrm{~W} / \mathrm{m}^{2} \mathrm{~K}$. As explained in earlier section, $350^{\circ}$ roll angle corresponds to the point on the roll where the roll comes in contact with the melt $360^{\circ}$ roll angle corresponds to the kissing point of the rolls.

In Fig. 16, six roll angles have been taken to study the temperature distribution across the through thickness. These roll angles are $90^{\circ}, 180^{\circ}, 270^{\circ}, 350^{\circ}, 355^{\circ}$, and $360^{\circ} .90^{\circ}, 180^{\circ}$, and $270^{\circ}$ corresponds to the roll region not in contact with the strip and $355^{\circ}$ correspond to the middle point of the roll region in contact with the strip.

As can be seen in Fig. 16, for cases of $355^{\circ}$ and $360^{\circ}$, there is a steep temperature drop from the outer surface till the through thickness value of $27 \mathrm{~mm}$ and after that the temperature is nearly constant. In case of $350^{\circ}$ also, the temperature drop is steep, but only till $7 \mathrm{~mm}$ of through thickness and after that the temperature is nearly constant. In case of $90^{\circ}, 180^{\circ}$, and $270^{\circ}$, the temperature is constant at the outer surface and then gradually drops. This is because, the temperature distribution along the outer surface is dictated by the heat transfer between the roll and atmosphere which is very low compared to the heat transfer coefficient between rolls and water. The drop in temperature is also a function of position for cases of $90^{\circ}, 180^{\circ}$, and $270^{\circ}$. The drop is more in case of $90^{\circ}$, which is more near the strip exit compared to the temperature drop for $180^{\circ}$ and $270^{\circ}$ cases. This high temperature gradient suggests that the magnitude of thermally induced stresses will be higher for the roll region in contact with the strip compared to the roll region not in contact with the strip.

\section{Conclusions}

The present study indicates that inlet velocity, contact strip/roll heat transfer coefficient, alloy composition, and melt superheat are the main process variables which affect the size and shape of sump in the melt regions between the rolls. Re- 
duction of centerline segregation within the strips involves the minimization of sump depth. Decrease in the sump depth can be achieved by lowering the casting speed, increasing the heat transfer between the strip and the rolls and using a lower solute composition alloy. Mean strip exit temperatures across the through-thickness of the strip is also affected by inlet velocity of the melt and contact strip/roll heat transfer coefficient. It has been shown that at lower contact strip/roll heat transfer coefficient and higher inlet velocity of melt lead to higher values of mean strip exit temperatures and higher temperature difference between the surface and the center of the strip. A higher thermal gradient within the strip generates large thermally induced stresses, which can lead to cracking of the surface of these strips.

The results of this work have shown that there exist a narrow range of operating variables, which can lead to minimization of sump depth, and thereby decreasing the casting defects like centerline segregation associated with it.

The temperature distribution at the surface and inside the roll was also studied. The temperature distribution at the surface not in contact with the rolls does not depend on the strip/roll heat transfer coefficient, whereas the temperature distribution at the surface of the rolls in contact with the melt is strongly dependent on the inlet velocity and the strip/roll heat transfer coefficient. The temperature gradient across the through thickness of the roll for the regions in contact with the strip was found to be much higher than the roll regions not in contact with the strip. During each revolution the roll goes through a thermal cycle which leads to thermally induced stresses. Excessive stress may cause deformation or warping of the roll. Stress analysis of strip and roll is presented in the next paper by the authors.

\section{Nomenclature}

$C_{\mathrm{p}}$ Specific heat $(\mathrm{J} / \mathrm{kg} \mathrm{K})$

$d$ Thickness of the solidified strip (m)

$D$ Diameter of the inlet (m)

$E$ Sensible heat $(\mathrm{J} / \mathrm{kg})$

$h_{\text {contact,strip/roll }}$ Contact heat transfer coefficient between the strip and the rolls $\left(\mathrm{W} / \mathrm{m}^{2} \mathrm{~K}\right)$

$h_{\text {conv,water/roll }}$ Convective heat transfer coefficient between water and the rolls $\left(\mathrm{W} / \mathrm{m}^{2} \mathrm{~K}\right)$

$h_{\text {effective }}$ Effective heat transfer coefficient between the rolls and atmosphere $\left(\mathrm{W} / \mathrm{m}^{2} \mathrm{~K}\right)$

$H_{f}$ Heat of fusion of aluminum $(\mathrm{J} / \mathrm{kg})$

HTC Strip/roll heat transfer coefficient $\left(\mathrm{W} / \mathrm{m}^{2} \mathrm{~K}\right)$ (same as $h_{\text {contact,strip/roll }}$ )

$k$ Kinetic energy of turbulence $\left(\mathrm{m}^{2} / \mathrm{s}^{2}\right)$

$k^{\prime}$ Thermal conductivity of alloy (W/m K)

$k_{\text {atm }}$ Thermal conductivity of atmosphere $(\mathrm{W} / \mathrm{m} \mathrm{K})$

$k_{\text {roll }}$ Thermal conductivity of the rolls $(\mathrm{W} / \mathrm{m} \mathrm{K})$

$k_{\text {water }}$ Thermal conductivity of water $(\mathrm{W} / \mathrm{m} \mathrm{K})$

$L$ Distance between the inlet and the kissing point of the rolls $(\mathrm{m})$

$P$ Pressure $(\mathrm{Pa})$

$q_{\text {atm }}$ Heat transfer to the atmosphere from the rolls $\left(\mathrm{W} / \mathrm{m}^{2}\right)$

$q_{\text {roll }}$ Heat transfer to roll from strip (W/m $\left.{ }^{2}\right)$

$q_{\text {water }}$ Heat transfer to water from roll $\left(\mathrm{W} / \mathrm{m}^{2}\right)$ $r_{\text {through }}$ Through Thickness of the rolls (m)

$r$ Radius of inlet $(\mathrm{m})$

$R_{\text {inner }}$ Inner radius of the rolls (m)

$R_{\text {outer }}$ Outer radius of the rolls (m)

$s$ Sump depth (m)

Superheat Superheat of alloy (K) (same as $T_{\text {superheat }}$ )

$t$ Distance across the thickness of the strip (mm)

$T$ Temperature (K)

$T_{\text {inlet }}$ Inlet temperature of melt $(\mathrm{K})$

$T_{\text {liquid }}$ Melting temperature of alloy (K)

$T_{\text {liquidus }}$ Liquidus temperature (K)

$T_{\text {refatm }}$ Reference temperature of atmosphere (K)

$T_{\text {ref,roll }}$ Reference temperature of the rolls (K)

$T_{\text {ref,water }}$ Reference temperature of water $(\mathrm{K})$

$T_{\text {solidus }}$ Solidus temperature (K)

$T_{\text {superhaet }}$ Melt superheat (K)

$u \mathrm{x}$ (horizontal) component of velocity $(\mathrm{m} / \mathrm{s})$

$u_{\text {normal,roll }}$ Normal velocity of the rolls $(\mathrm{m} / \mathrm{s})$

$u_{\text {normal,strip }}$ Normal velocity of the strip (m/s)

$u_{\text {tang,roll }}$ Tangential velocity of the rolls $(\mathrm{m} / \mathrm{s})$

$u_{\text {tang,strip }}$ Tangential velocity of the strip $(\mathrm{m} / \mathrm{s})$

$v$ y(vertical) component of velocity $(\mathrm{m} / \mathrm{s})$

$v_{\text {inlet }}$ Inlet velocity of melt $(\mathrm{m} / \mathrm{s})$

Vel. Inlet velocity of melt $(\mathrm{m} / \mathrm{s})$ (same as $\left.v_{\text {inlet }}\right)$

$x$ Cartesian coordinate in horizontal direction

$y$ Cartesian coordinate in vertical direction

\section{Greek Symbols}

$\delta$ Characteristic thickness of the shear width (m)

$\varepsilon$ Dissipation rate of kinetic energy $\left(\mathrm{m}^{2} / \mathrm{s}^{3}\right)$

$\bar{\theta}$ Angle (deg)

$\phi$ Angle of contact between strip and roll (deg)

$\rho$ Density $\left(\mathrm{kg} / \mathrm{m}^{3}\right)$

$\rho_{\text {liquid }}$ Density of liquid phase $\left(\mathrm{kg} / \mathrm{m}^{3}\right)$

$\rho_{\text {solid }}$ Density of solid phase $\left(\mathrm{kg} / \mathrm{m}^{3}\right)$

$\omega$ Angular velocity of the rolls $(\mathrm{rad} / \mathrm{s})$

\section{Acknowledgements}

The funding for this research has been provided by the National Science Foundation under the grant number DMI9900140. The use of computer time on Cray T94 at The Ohio Supercomputer Center is gratefully acknowledged.

\section{REFERENCES}

1) S. Caron, E. Essadiqi, F. G. Hamel and J. Masounave: Light Metals (1990) 967-973.

2) K. Miyazawa and J. Szekely: Metall. Trans. 12A (1981) 1047-1056.

3) T. Saitoh, H. Hojo, H. Yaguchi and C. K. Kang: Metall. Trans. 20B (1989) 381-390.

4) H. Murakami, M. Hasan and R. I. L. Guthrie: $1992-10^{\text {th }}$ PTD Conference Proceedings (1992) pp. 347-354.

5) S. H. Seyedein and M. Hasan: Numerical Heat Transfer, Part A 32 (1997) 221-246.

6) A. Mo and S. H. Hoydal: Modeling of Casting, Welding and Advanced Solidification Processes VI (1993) pp. 671-677.

7) J. G. Chang and C.-I. Weng: Int. J. for Num. Methods in Engineering, 40 (1997) 493-509.

8) "FIDAP-Theory Manual", Fluid Dynamics Analysis Package, FIDAP 7.0, (1993) pp. 2-33-2-36.

9) A. V. Reddy and C. Beckermann: Metall. Trans. 28B (1997) 479-489. 